\title{
ENSINO DE LITERATURA E FORMAÇÃO DE LEITORES NA REDE PÚBLICA: RELATO DE EXPERIÊNCIA
}

Karolaine Claudia dos Santos*

Faculdade de Presidente Prudente - FAPEPE, Presidente Prudente, SP.

\section{RESUMO}

Este artigo apresenta um relato de experiência de ensino desenvolvido por meio de um trabalho teórico-prático com os alunos do curso de licenciatura em Letras da FAPEPE, com a apresentação do seminário tivemos que elaborar e vivenciar as etapas de uma sequência expandida, refletindo sobre possibilidades para o ensino da Literatura.

Palavras-chave: Sequência expandida. Literatura. Literatura juvenil. Ensino de literatura.

\begin{abstract}
This article presents an account of teaching experience developed through a theoretical-practical work with the students of the undergraduation course in Literature of FAPEPE, with the presentation of the seminar we had to elaborate and experience the stages of an expanded sequence, reflecting on possibilities for the teaching of Literature.
\end{abstract}

Keywords: Expanded sequence. Literature. Juvenile literature. Literature teaching. 


\section{INTRODUÇÃO}

Neste trabalho, apresentamos uma proposta desenvolvida pela disciplina Fundamentos e Práticas do Ensino da Língua Portuguesa, ministrada no curso de Letras da Faculdade de Presidente Prudente - FAPEPE. No primeiro semestre de 2016, durante a aula, discutíamos a dificuldade de ensinar Literatura na educação básica, sem a transformar em mero pretexto para discussão de gramática e sem tratar, exclusivamente, das características de escolas literárias, como geralmente ocorre nos livros didáticos. Assim, com a mediação da docente responsável pela disciplina, deparamo-nos com o procedimento metodológico intitulado Sequência Expandida, que visa ao desenvolvimento de aulas nas quais a ênfase esteja no teor artístico e singular da Literatura.

O plano de aula, bem como sua aplicação, apresentou as seguintes etapas: motivação, introdução do universo do livro, apresentação de cinco personagens e a bolsa amarela, em um cenário característico. Na etapa seguinte, introdução, apresentação de dados sobre a autora, além de críticas literárias sobre a obra, com levantamento de conhecimento prévios dos leitores. $\mathrm{Na}$ terceira etapa, leitura, houve realização de leitura compartilhada de um trecho do romance, com momentos de conflito na narrativa. No primeiro momento, realizou-se a interpretação com levantamento das impressões dos leitores quanto ao trecho lido, com destaque para os elementos da narrativa; no segundo, a contextualização, ou seja, a compreensão da obra em seu contexto de produção, com destaque para os aspectos teórico, histórico e presentificador. Na segunda interpretação, ocorre a leitura aprofundada de um aspecto da obra, no caso, com ênfase na construção e atuação da personagem feminina Raquel, encontrando correspondências na mudança da fase infantil para adulta. E, no último, a expansão que é a construção de diálogos intertextuais com a personagem de Cecília Meireles e do cantor Toquinho.

O objetivo da atividade foi elaborarmos e vivenciarmos as etapas de uma Sequência Expandida, refletindo sobre possibilidades para o ensino da Literatura. Tínhamos que preparar um plano de aula e o aplicar durante o seminário, enfatizando o processo de leitura do romance $A$ bolsa Amarela, de Lygia Bojunga.

\section{Considerações iniciais}

O ensino da Literatura na escola é fundamental, já que proporciona aos alunos facilidade na compreensão da leitura e escrita.

De acordo com Cosson (2009), o processo de letramento literário compreende não somente uma dimensão diferenciada do uso social da escrita, mas também assegura o seu efetivo domínio, oferecendo aos alunos um modo de ver e de viver no mundo.

Contudo, ensinar literatura é um processo importante para a formação de leitores, reconhecer os textos utilitários e não utilitários. O ensino de literatura é essencial para ampliação do conhecimento na contextualização da obra, compreendendo os problemas frequentes daquela época.

Assim, proporciona aos alunos um âmbito maior no universo do livro. Como menciona

o autor

A interpretação se dá em dois momentos, um interior e outro exterior. 0 momento interior compreende a decifração, é chamado de "encontro do leitor com a obra" e não pode ser de forma alguma substituído por algum tipo de intermediação como resumo de livro, filmes, minisséries. Já o momento exterior é a materialização da interpretação como ato de construção de sentido em uma determinada comunidade. (COSSON, 2009, p.65) 
Apesar dos desafios enfrentados pelos adolescentes com a era da tecnologia como vídeo games e bombardeamento de imagens não dispensam as instruções escritas. A literatura revela-se como uma prática fundamental reconstruída pela força da palavra. Ela é plena de saberes sobre o mundo porque gera uma experiência literária que permite compreender a vida por meio da experiência do outro, assim como vivenciar essa experiência literária, sendo um processo formativo da linguagem, do leitor e do escritor. Como aborda Cosson (2009)

$\mathrm{Na}$ escola é preciso compartilhar a interpretação e ampliar os sentidos construídos individualmente. A razão disso é que, por meio do compartilhamento de suas interpretações os leitores ganham consciência que são membros de uma coletividade e de que essa coletividade fortalece e amplia seus horizontes de leitura. (COSSON, 2009, p.65)

A literatura permite que o leitor entenda seus sentimentos de maneira precisa, ou seja, esclarecer o que não se sabe expressar e como dizer ao mundo.

É por essa função, como aponta o autor, que o mundo se torna compreensível, transformando a materialidade em palavras de cores, odores, sabores e formas intensamente humanas que a literatura tem e precisa manter um lugar especial nas escolas, por essa razão é fundamental haver o letramento literário.

A literatura tem a função de aproximar fantasia da realidade como ainda destaca Candido (1972)

A fantasia quase nunca é pura. Ela se refere constantemente a alguma realidade: natural, paisagem, sentimento, fato, desejo de explicação, costume, problemas humanos etc. Eis por que surge a indagação sobre o vínculo entre fantasia e realidade, que pode servir de entrada para pensar na função da literatura (CANDIDO, 1972, p.804)

A literatura permite que o leitor construa a sua interpretação durante a leitura contribuindo com sua formação. Ademais, o autor enfatiza que

Mas ainda: a ideia de função provoca não apenas uma certa inclinação para o lado do valor, mas para o lado da pessoa: no caso, o escritor (que produz a obra) e o leitor, coletivamente o público (que recebe o seu impacto). De fato, quando falamos em função no domínio da literatura, pensamos imediatamente (1) em função da literatura como um todo; (2) em função de uma determinada obra; (3) em função do autor, tudo referido aos receptores (CANDIDO, 1972, p.803)

É visível que no gosto de ampla faixa da população, as pessoas têm confundido a obra utilitária com a não utilitária:

Observa-se que, cada vez mais, no gosto de ampla faixa dos cidadãos a leitura dessas obras tem pouco ou nenhum espaço, fazendo-se presente a leitura de títulos de caráter utilitário (como, por exemplo, os livros de autoajuda ou obras de outras naturezas) ou de títulos voltados sobretudo ao entretenimento (CECCANTINI, 2009, p.208)

Apesar de alguns ainda realizarem essas leituras fornecidas pela mídia do ponto de vista do entretenimento, ainda é baixo o número de leitores no Brasil.

Assim apesar de nunca se ter lido tanto no Brasil, ainda se lê bem menos do que o desejável, na medida em que grande faixas da população permanecem numa posição periférica em relação á leitura, sobretudo 
quando o critério de análise se apega a uma dimensão mais qualitativa, seja no que concerne aos suportes (livros ou outros materiais de leitura), á escolha de obras(literárias ou não-literárias) e á consistência e profundidade das leituras [...] a leitura hoje está inserida e que depende da ação de inúmeras variáveis- ordem política, econômica, educacional [...](CECCANTINI, 2009, p.208)

Percebemos a importância da escola desse processo na formação de alunos leitores, inclusive de leitura, tendo acesso a obras de qualidade, ampliando repertório dos alunos com o objetivo de vivenciar experiências da vida.

Esse processo exige um animador de leitura desde as séries iniciais, promovendo o contato da criança com os livros e outros materiais na medida em que essas crianças se transformem em jovens leitores e que adquiram conhecimentos das obras utilitárias.

\section{Sequência expandida}

A sequência expandida é a aprendizagem pela literatura que envolve sete etapas: motivação, introdução, leitura, primeira interpretação, contextualização, segunda interpretação e expansão.

Essa proposta visa trazer uma alternativa a prática docente, tornando o ensino de literatura dinâmico, atraente e preciso aos alunos, fortalecendo a leitura de maneira prazerosa. Cosson (2014), propõe-nos que

(...) há aqueles que desejam muito estudar literatura ou qualquer outra coisa. Todavia, seja por falta de referências culturais ou pela maneira como a literatura lhes é retratada, ela se torna inacessível. Para eles, a literatura é um mistério, cuja iniciação está fora de seu alcance. (COSSON, 2014, p.10-11)

Como mencionado anteriormente, esse processo envolve sete etapas. A primeira etapa é a motivação, que corresponde à introdução dos alunos no universo do livro a ser lido. A motivação pode ser apresentada de várias formas com música, com teatro e com dança.

A introdução é a apresentação do autor e da obra, o docente deve levar em consideração que algum aluno já deve ter ouvido falar do livro ou do autor e aproveitar esse conhecimento para localizar com economia os dados: críticos, biográficos e bibliográficos.

Durante a leitura, convém que seja feita prioritariamente extraclasse, com a mediação do docente que escolhe algum capítulo, de acordo com o tempo programado, para compreender a obra com cautela e para que a leitura não possa ser tão curta a ponto de obter informações necessárias para a compreensão da obra como também, muito longa a fim de desviar atenção dos alunos tornando cansativo. $O$ docente pode trazer outros gêneros que estabelecem relação com o texto trabalhado ou a fotografia da obra.

Primeira interpretação destina-se a uma compreensão geral da obra. O objetivo dessa etapa é levar o aluno a traduzir a impressão geral do título, temática e o impacto que ele teve sobre sua sensibilidade de leitor, ou melhor, como o leitor recebeu e assimilou essa obra. As perguntas podem ser elaboradas utilizando os elementos da narrativa.

A contextualização compreende o aprofundamento da leitura por meio do contexto que a obra traz consigo. Com vários contextos que podem ser explorados relacionar o estilo da linguagem com o passado, identificar características que remete ao período, reconhecer a influência do período na construção da obra. Na contextualização teórica, há a procura por tornar explícitas as ideias que sustentam ou estão encenadas na obra. Busca-se verificar como em certas 
obras determinados conceitos são fundamentais naquele período, compreender e entender melhor a obra desde que o leitor identifique tais elementos durante a leitura.

História mais próxima do tradicional, a contextualização histórica abre a obra para a época na qual encena ou no período de sua publicação. Desse modo, o leitor relaciona os personagens, espaço e a linguagem com determinado período.

A estilística está centrada nos estilos de época ou nos períodos literários como Trovadorismo, Classicismo, Quinhentismo, Barroco, Arcadismo, Romantismo etc. Cada qual com um estilo, temática e uma marca histórica.

Poética diz respeito à estruturação ou composição da obra. Pode-se, no caso da poesia, analisar figuras de linguagem e questões relativas à rima, estrofes, versificação ou a categorias como personagem, narrador, tempo, espaço e outras no caso de narrativas literárias, por meio destes recursos é possível reconhecer a expressão, desejo, sofrimentos do eu lírico.

Crítica trata da recepção do texto literário. Nesse caso, ela pode tanto se ocupar da crítica em suas diversas vertentes ou da história da edição da obra, além de observar diferentes pontos de vista e fundamentar a coerência e a coesão dessas análises, ampliando as vertentes.

Presentificadora é a contextualização que busca correspondência da obra com o presente da leitura. Trata-se, por assim dizer, de uma atualização. Cabe ao mediador propor métodos para que os alunos relacionem com um fato contemporâneo seja na temática, personagens, cultura e na linguagem. Outro caminho é a busca da diferença, ou seja, as mudanças com o uso da tecnologia inclusive vestimentas, costumes e as variações linguísticas, ou melhor, problemas que foram superados por meio de revoluções.

\section{Como ensinar a literatura?}

O letramento literário se faz por meio das práticas sociais, podendo utilizar a intertextualidade, a conexão, a visualização, a inferência, a sumarização, a síntese e estratégias de leitura (pré-leitura, leitura e pós leitura).

Os estudantes, ao consultarem o texto, é fundamental identificar o gênero, ou melhor, a forma, a estrutura e o conteúdo com a ajuda do docente. Como cita Junqueira (2010)

O letramento literário enquanto construção literária dos sentidos se faz indagando ao texto quem e quando diz, o que diz, como diz, para que diz e para quem diz. Respostas que só podem ser obtidas quando se examinam os detalhes do texto, configura-se um contexto e se insere a obra em um diálogo com outros tantos textos. Tais procedimentos informam que o objetivo desse modo de ler passa pelo desvelamento das informações do texto e pela aprendizagem de estratégias de leitura para chegar à formação do repertório do leitor (JUNQUEIRA, 2010, p.103)

O mediador precisa definir o tipo de leitura, como será a leitura, podendo utilizar esta oficina. O docente necessita de cautela na utilização de alguns textos literários, inclusive fragmentado, causando a perda do sentido do letramento literário, já que os alunos não conhecem a obra, exige-se um processo de construção.

Para facilitar a compreensão do texto e torná-lo dinâmico, propor conexões com a temática do cotidiano dos alunos. O docente, na realização da leitura, pode utilizar como estratégia os elementos de visualização, traçando um caminho para a temática da obra.

O processo de leitura utiliza duas fontes de informação da leitura: a informação visual ou por meio dos olhos, que consiste na informação proveniente do texto, e a informação não-visual ou de trás dos olhos, que consiste no conjunto de conhecimentos do leitor. Assim, a partir da 
informação do texto e de seus próprios conhecimentos, o leitor construirá o significado em um processo [...] ( KLEIMAN, 2013, p.8)

A próxima estratégia é a inferência que consiste em reunir pistas de um texto, orientando o leitor a obter uma conclusão sobre o que está lendo.

Outra ferramenta essencial na leitura é a sumarização, sendo a seleção dos elementos importantes do texto que necessita da orientação do mediador para organizar os alunos nas anotações dos capítulos e fragmentos importantes.

$\mathrm{E}$, por último, a síntese que não significa um resumo do texto, mas sim a opinião pessoal do leitor conforme o que é lido, apresentando as expectativas e sensações de leitura.

Com a construção e aplicação de uma sequência expandida é possível aprender as estratégias para o desenvolvimento do letramento literário, produzindo leituras significativas e aprendizagem significativa da literatura.

Para aplicação, foi selecionado o romance clássico de Lygia Bojunga A bolsa amarela, uma obra popular que utiliza uma linguagem e temática do cotidiano de fácil compreensão aos adolescentes, a fim de se aplicar a sequência expandida.

Iniciando a motivação, apresentou-se um breve teatro com seis personagens: Raquel, irmão, duas irmãs, mãe e a tia Brunilda, utilizando-se um cenário propício. Inicialmente, Tia Brunilda traz presentes aos sobrinhos, todos escolhem, enfatizando que Raquel será a última por ser a filha caçula, sobrando a ela apenas a bolsa amarela. A menina descreve a bolsa amarela e o que pretende guardar destacando a sua importância. Na segunda cena, aborda o conserto do zíper da bolsa e o pronunciamento da menina:

"Escuta aqui fecho, eu quero guardar umas coisas bem guardadas aqui [...] às vezes vão abrindo a bolsa da gente assim sem mais nem menos; se isso acontecer você precisa enguiçar, viu?" E procede o diálogo entre Raquel e o fecho.

Na segunda etapa, a introdução foi apresentação dos dados da autora tais como data de nascimento, naturalidade, filiações, carreira, estilo, obras e prêmios como Andersen, Jabuti e memorial etc. Em seguida, houve apresentação da capa do livro destacando a cor da bolsa: amarela. E com o enigma do desenho abaixo do zíper.

$\mathrm{Na}$ terceira etapa, leitura, cada aluno lê um parágrafo. Foram selecionados os capítulos 16,17,18 e 21 que descrevem a família de Raquel e o primeiro desejo em se tornar escritora porque amava inventar gente, endereço, telefone, casa, rua, enfim um mundo de coisas. $\mathrm{O}$ segundo desejo em ser menino porque acredita que "podem tudo" nos jogos, brincadeiras e posição chefe de família; outro desejo era se tornar adulta para expressar o que sente e possuir autonomia no modo de pensar e de sonhar. Os alunos atenciosamente realizaram a leitura.

$\mathrm{Na}$ quarta etapa, houve os seguintes questionamentos:

- O romance é narrado em primeira, segunda ou terceira pessoa?

- Onde ocorre o romance?

- Cite os personagens principais e secundários?

- O tempo é cronológico ou psicológico?

- Descreva uma situação-problema?

A quinta etapa é a contextualização, ressaltando a teoria em que determinados conceitos são fundamentais como: a mulher submissa ao homem -, tia Brunilda ameaçava o marido a realizar seus caprichos, caso contrário, procuraria um emprego, seno esse o motivo que Raquel desejar ser menino, apesar de escondê-lo. A predominância da voz masculina na família.

$\mathrm{Na}$ contextualização histórica, a obra tem como característica o estilo da autora e tema abordado naquele período, inclusive pelo autor Monteiro Lobato, por meio da liberdade de 
imaginação, uma chave para a resolução de conflitos, misturando o real com o imaginário e temas problemáticos.

A contextualização presentificadora é a diferença de valores, dos quais as crianças são liberadas a brincarem como quiserem sem interrupção do sexo masculino ou feminino. Atualmente, o entretenimento das crianças é por meio dos aparelhos tecnológicos e outro ponto é a liberdade da mulher.

Na sexta etapa, segunda interpretação, foram levantadas as seguintes questões:

- Quais são os principais desejos de Raquel?

- Qual é a relação do desejo de Raquel com a bolsa amarela?

- Descreva os valores daquele período? Cite as mudanças.

- Como Raquel se sentia?

- Qual é a relação da Raquel com a família?

E, por último, a expansão, nessa etapa foram analisados dois gênros: o gênero letra de música - Aquarela de Toquinho - e o gênero poema -Criança de Cecília Meireles.

Os alunos apontaram que a música possui semelhança com a história de Raquel, ou melhor, com a imaginação, podendo se tornar real como mencionado anteriormente uma mistura do real com o imaginário sem limites. Ambos são expressos na folha de papel.

O mesmo levantou a hipótese na quinta estrofe da letra de música "Um menino caminha e caminhando chega no muro. E ali logo em frente, a esperar pela gente, o futuro está [...] Descreve as fases da vida, a voz poética do texto deixou o lado de criança e agora mostra a fase adulta com responsabilidades e regras a serem cumpridas como cidadãos.

Outro texto analisado é o poema Criança de Cecília Meireles, que destaca o sofrimento pela incompreensão da família de uma criança se fazendo pensativa e confusa. Reconheceram situações-problema (temática) em comum, Raquel uma menina encantadora e com imaginação incrível e amadurecida com ponto de vista que muitos adultos não possuem.

Apesar de viver de imaginação e sozinha, criando amigos e personagens, não deixa de sonhar e de usufruir da vida. Analisaram o trocadilho na primeira estrofe entre o segundo e terceiro verso "sofre sozinho" e "sozinho sofre" com os desejos que Raquel oculta por desejar oposto como ser menino e adulta.

\section{CONSIDERAÇÕES FINAIS}

Com a construção e a aplicação da Sequência Expandida supramencionada, foi possível aprendermos estratégias para o desenvolvimento do letramento literário, produzindo leituras significativas, aprendizagem da literatura e aprendizagem sobre a literatura. Com isso, nos sentimos mais preparados para o desenvolvimento da docência como futuros professores de Língua Portuguesa.

Reconhecer a vantagem da literatura nas aulas e apropriação da escrita e das práticas sociais que estão relacionadas, possibilitando retornar ao passado e comparar com o presente.

O texto literário permite encontrar-se na sociedade ou na cultura, nas quais está inserido, tendo um domínio maior das palavras, expressando desejos e pensamentos com clareza.

Por meio dessa oficina, é possível que os docentes saibam como conduzir as aulas de literatura nas escolas, deixando o método tradicional de ensinar os períodos literários, época e características.

\section{REFERÊNCIAS}

CECCANTINI, J. L. C. T. Leitura e literatura infanto-juvenil: memória de Gramado. São Paulo: Cultura acadêmica - Assis, SP: ANEP, 2004. 
COSSON, Rildo. Letramento literário: educação para vida. Vida e Educação. Fortaleza, v. 10, p. 1416, 2006a.

. Letramento literário: teoria e prática. São Paulo: Contexto, $2006 \mathrm{~b}$.

CÂNDIDO, Antônio. O direito à Literatura. In: Vários escritos. São Paulo: Duas Cidades, 1995.

KLEIMAN, Angela B. Preciso "ensinar" o letramento? Não basta ensinar a ler e a escrever?

Coleção Linguagem e letramento em foco: linguagem nas séries iniciais. Ministério da Educação.

Cefiel/IEL. UNICAMP, 2005,2010-2013 